\title{
Countermeasures for pasture associated laminitis
}

\author{
Patricia A. Harris \\ Equine Studies Group, WALTHAM Centre For Pet Nutrition, Melton Mowbray, UK
}

\begin{abstract}
Summary
Laminitis occurs all around the world in horses and ponies and has major welfare implications. Recognising and treating the condition in its early stages so that the pain and suffering is kept to a minimum is obviously important. However, it would be preferable to be able to recommend certain interventions/ countermeasures that avoid or prevent the condition from occurring in the first place. This paper will outline some of the potential countermeasures that may help to reduce the incidence or severity of this important condition.
\end{abstract}

Keywords: laminitis, countermeasures, pasture, ponies, insulin resistance.

\section{Maßnahmen gegen die weideassoziierte Rehe}

Die Hufrehe stellt ein weltweites Gesundheitsproblem von Pferden und Ponies dar. Die Erkennung und Behandlung der Erkrankung im frühen Stadium ist für die die Reduzierung von Schmerz und Leiden auf ein Minimun unerlässlich. Vorteilhaft wäre die Möglichkeit einer effektiven Empfehlung von Gegenmaßnahmen bzw. Interventionen, um die Entstehung der Erkrankung überhaupt zu verhindern bzw. ihr vorzubeugen. Dieser Beitrag will einige potentielle Gegenmaßnahmen aufzeigen, welche helfen, die Inzidenz und Schwere des wichtigen Problems der weideassoziierten Rehe zu mindern

Schlüsselwörter: Rehe, Weide, weideassoziiert, Gegenmaßnahme, Pony, Insulinresistenz

\section{Introduction}

Laminitis, is truly a global condition of horses and ponies with major welfare implications. Despite this we still do not fully understand several aspects of the condition, as encountered under natural conditions; from its epidemiology to its pathogenesis (Allen 2004, Bailey et al. 2004) e.g. despite anecdotal reports, reviews and surveys such as that carried out in the US (2000) which state that the most common perceived cause of laminitis is the ingestion of 'lush' pasture, very few in depth epidemiological studies have in fact been undertaken into this as reviewed by Alford et al. 2001. Those studies that have been carried out often do not have sufficient numbers to allow real definition of the risk factors. Information therefore tends to be based on the accepted clinical views e.g. fat ponies are most susceptible.

Research has, however, been carried out which confirms, for example, that over-feeding of cereals can reproducibly cause laminitis (Obel 1948), as can bolus feeding of a commercial inulin type fructan (Pollitt et al. 2003). Research has recently primarily concentrated on such models and tried, quite logically, to understand how such manipulations result in laminitis. However, the majority of animals that suffer from laminitis have not been fed ad lib cereals or ingested large amounts of pure fructans as a bolus and not all of a group of ponies or horses out on a particular pasture will develop laminitis. Despite the lack of published scientific studies it would not perhaps be disputed by most veterinarians and horse owners that most cases of laminitis occur in animals out at pasture and therefore this paper concentrates on this aspect.
Turning certain ponies out onto 'stressed' (i.e. environmental conditions are sub-optimal for growth) or perhaps more commonly in Europe 'lush' (i.e. green, actively photosynthetic) pastures in the spring and autumn is a common triggering factor for the development of laminitis. Currently it is thought that the high levels of water-soluble carbohydrates (which include the simple sugars as well as the more complex storage carbohydrate: Fructans - the main storage carbohydrate in temperate grasses) and/or starch may be involved in this process as illustrated in figure 1. Dr Chris Pollit and his team in Australia have certainly confirmed that giving relatively large amounts of a particular fructan as a bolus can reliably induce laminitis in the horse (Pollitt 2003). It is considered that as for other mammals the horse does not have the necessary enzymes to digest fructans directly within the small intestine. Fructans therefore pass into the hindgut where they are readily fermented, in a similar manner to starch that is not digested in the small intestine following the ingestion of too large a cereal or other high starch containing meal.

Rapid fermentation will lead to the swift production of lactic acid, in particular, and the lowering of the $\mathrm{pH}$ upsetting the bacterial/microbial balance. When this occurs and the $\mathrm{pH}$ drops below a certain critical point, bacteria that are not able to survive under such conditions may die and release endotoxins and other such compounds into the hindgut. In addition there may be overgrowth of certain bacteria that can survive in such conditions which in turn release/produce other compounds into the large intestine. Changes in the 
Ingestion of an

'excessive' amount of rapidly fermentable carbohydrate

e.g an 'overload' of starch from cereal grains or sugar and/or fructan and/or starch from pasture

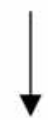

* Too much reaches hindgut - rapidly fermented

* Produces lactic acid - $\mathrm{pH}$ decreases - increases mucosal permeability

* Some bacteria die releasing endotoxin and other unwanted factors

* Other bacteria change internal metabolism in response to the $\mathrm{pH}$ decrease - produce for example certain amines

* Increased concentration of various substances including exotoxins (bacterial proteases) in particular Matrix metalloproteinase (MMP) activating factors, as well as amines within the GIT

* With change in permeability increased risk that certain factors cross into the blood in increased amounts.

Increase in circulating endotoxin and amine levels

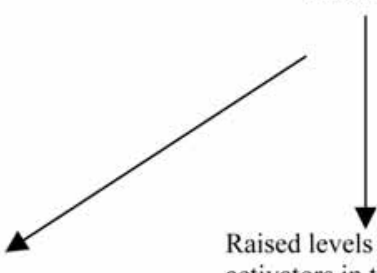

Raised levels of MMP activators in the blood (potentially coupled with an increase in blood flow so more BI. vessels of the hoof very reach the hoof

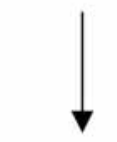
sensitive to certain amines leads to reduced blood flow to the foot

Increased endotoxins
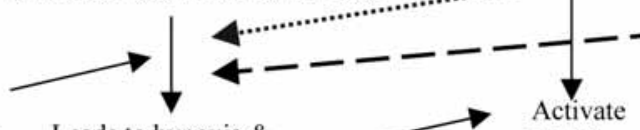

Leads to hypoxia \& reduced glucose reaching hoof tissue
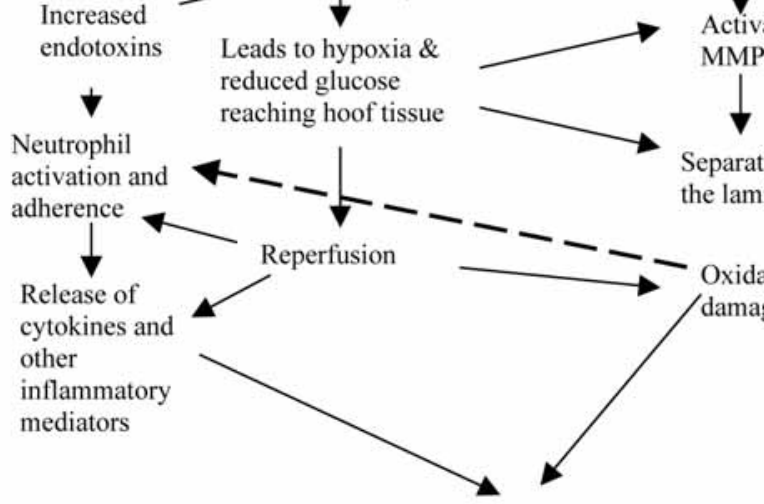

is

Separation of the laminae

more
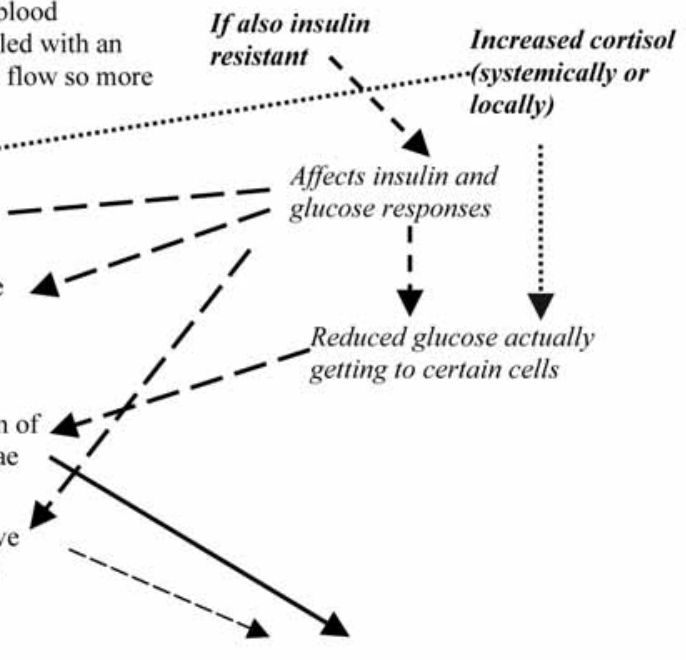

Activate

MMPs

Fig 1 The possible sequence of events in cereal overload or grass associated laminitis and the potential influence that insulin resistance and raised cortisol levels may have (Harris 2005).

Mögliche Ereignisfolgen und Zusammenhänge bei der Entstehung der Hafer- oder Weide-assoziierten Rehe und der mögliche Einfluss von Insulinresistenz und erhöhten Cortisolwerten.

mucosa due to the drop in $\mathrm{pH}$ and other factors may make it more permeable to such substances. A number of compounds, consequently may be absorbed into the blood in greater amounts than normal and have further effects, in particular within the feet (not necessarily directly), triggering the development of laminitis. These include the vasoactive amines that may potentiate a reduction in the blood flow to the feet and activators of various Matrix metalloproteinases, which may potentiate a more rapid and unwanted separation of the basement membrane between the lamellae (Elliott and Bailey 2006, Harris et al. 2006, Longland and Byrd 2006). These effects may be potentiated by the animal being insulin resistant as outlined below and Treiber et al. 2006.

\section{Countermeasures to avoid and prevent pasture associ- ated laminitis}

In this context we should consider countermeasures that include both passive 'avoidance' meaning' keeping out of the way' and active 'prevention' meaning' to keep from happening especially by taking precautionary action'. Ideally this would mean countermeasures, which are effective before there is separation of the lamellae. However, we really need to understand why particular pastures at certain times result in laminitis in certain individuals in order for us to consider appropriate and effective countermeasures for pasture-associated laminitis. Only once we really appreciate this we can develop appropriate countermeasures to help us to avoid and prevent laminitis. Obviously as pasture associated laminitis occurs at pasture 
then the easiest way to avoid the condition is to prevent access to pasture and to feed forage alternatives that are known to be low in rapidly fermentable material. For the majority of horses total restriction is not always a viable or desired option for financial, welfare and health reasons (Davidson and Harris 2002). It also may not be necessary for those animals that are not predisposed to this condition. So the first stage in our countermeasures would ideally be to determine whether our individual horse had an increased risk of laminitis or not.

\section{Identification of individual level of predisposition}

Why certain individuals and not others may be affected when all on the same managemental regimen is the subject of much interest. Individual variations in GIT function or peripheral blood vessel responsiveness may play a role (Bailey et al 2004), as may the level of insulin resistance. Recent work has also started to look in more detail at the genetic aspects.

\section{Role of Genetic predisposition}

One recent study in Welsh and Dartmoor ponies, for example, suggests a possible genetic component (Splan et al 2005). Further work is needed within this group and other unrelated animals prone to the condition to evaluate this further.

\section{Role of Individual differences in GIT processes}

Recent work from Germany (Coenen et al. 2005) showed that Jerusalem artichoke (contains inulin: a fructan) was more effective in stimulating microbial activity (as assessed by the rise in hydrogen and methane exhalation post ingestion) than a meal of oats providing the same amount of hydrolysable carbohydrates. Interestingly, within this study there were large individual differences, which could be linked with individual levels of predisposition.

Role of Breed, condition score and the individual on insulin resistance

Glucose is important in maintaining lamellar integrity and has been shown to be essential for hoof explants in culture. Culture without glucose or inhibition of glycolysis also causes basement membrane zone separation under tension (Pass et al 1998). It has been well recognised, although there is again little objective data, that obese animals especially ponies are more prone to laminitis; this may in part be linked with mechanical trauma. However, it is likely that the risk for laminitis in obese horses is more appropriately attributed to the development of insulin resistance (Treiber et al., 2005a and b, Kronfeld et al. 2005a, Treiber et al. 2006). It has been suggested that there may be a progression of insulin resistance in laminitic prone ponies from compensated insulin resistance being a predisposing factor in healthy but genetically predisposed ponies through to a decompensated insulin resistance later in the course of the disease (Hess et al. 2005).

\section{Route forward}

A major aim for any countermeasure strategy would be to be able to identify apparently healthy ponies with a genetic predisposition for laminitis from their genotype, so that they can be given appropriate management.

The development of rapid and easy methods to determine insulin resistance reliably would help considerably in this aspect. However, determining individual variations in GIT function or peripheral blood vessel responsiveness may be more difficult.

Certainly it would seem advisable to consider countermeasures that aim to avoid or prevent both chronic insulin insensitivity (due to adaptation to glucose-yielding carbohydrates) and acute insulin resistance following rapid fermentation of sugar, starch and fructan. Countermeasures to reduce the risk of IR in certain breeds could include replacing, in the diet of healthy horses, starch and sugar based diets safely with appropriately formulated fat and fibre based feeds that produce a low glycaemic response (Kronfeld et al. 2005).

Encouraging people to monitoring bodyweight and condition score more regularly (Gee and Harris 2005) in order to try and maintain animals at a more optimal weight coupled with, wherever possible, maintaining regular exercise (Freestone et al. 1992) would be relatively simple countermeasures that could be implemented.

\section{Avoid high intakes of rapidly fermentable materials}

In particular for those animals identified at being at high risk of developing laminitis, although total restriction to pasture may be the ultimate countermeasure, a less dramatic solution would be to restrict access at high risk times of the year and the day.

This requires the identification and more detailed description of risk factors that result in the pasture containing high levels of rapidly fermentable material i.e. when is the best time to restrict access to pasture to reduce the risk of Laminitis (Longland and Byrd 2006)

This information should enable the development and testing of innovative pasture and feeding management strategies that avoid these risk factors, hence reducing the incidence of laminitis. As mentioned above few studies have looked at this but one in the US and one in the UK suggested an increased risk in May and May and June respectively (see Alford et al. 2001, Katz et al. 2001). Current thinking would be that laminitis could be largely avoided, especially in genetically predisposed animals, by grazing when the levels of starch, sugar and fructans were low. However, this may be difficult as this may vary from season to season; within any particular day, according to plant species, according to field topography and according to grazing patterns of individual animals (Longland and Byrd 2006). Much more information is needed with respect to this. However, currently some of the recommendations would include (see also Harris et al. 2006, Longland and Byrd 2006): not grazing temperate grass pastures during the growing season or as a minimum restrict turnout to very late at night or very early in the morning and removing them 
by mid morning at the latest. Avoid pastures that have not been managed properly and avoid in particular pastures that are in conditions that favour photosynthesis over growth (e.g. low temperatures with bright sunlight).

\section{Dietary and therapeutic agents that may prevent lam- initis.}

Again there has been little if any controlled trials that have tested interventions with feeds, dietary supplements, feed additives and drugs that work to prevent laminitis.

Two types of preventative agents could be considered: those that act once clinical signs are seen to minimise the severity, prevent the movement of the pedal bone and improve recovery rates and those, perhaps preferably, that could be given safely, maybe at key times of the year as discussed above, to reduce the risk of the condition even starting. Looking at figure 1 there are a number of avenues that could be approached. The streptogrammin antibiotic 'virginiamycin' for example 'has been successfully used and marketed to prevent pasture-induced laminitis by preventing the overgrowth of gram positive caecal bacteria' (see Bailey et al 2004). However, this is only available in Europe under special licence and anecdotally is not effective in all cases. Other aspects that need to be explored include the role of increased antioxidant supplementation, importance of hind gut buffers, role of agents that counter insulin resistance as well as those that prevent subsequent effects on the digital blood vessels and block the activation of MMPs. There is some preliminary scientific support for the use of some agents once clinical signs have occurred but 'field trials examining the effectiveness of these agents in naturally occurring cases will be required to establish their true value in the clinical situation' (Bailey et al. 2004). The results of the BEVA initiated practice based study on the factors affecting the return to soundness in acute pasture-associated laminitis will be of great interest in this area.

\section{Conclusion}

Unfortunately currently there is no hard data on effective countermeasures, only mechanistic evidence for avoiding risk factors and no randomised trials supporting prevention or therapy for any form of laminitis. There is however much to play for and research in this area is urgently required (Harris et al. 2006).

\section{References}

Alford P., Geller S., Richardson B., Slater M. et al (2001): A multi-center, matched case-control study of risk factors for equine laminitis Preventative Veterinary Medicine 49, 209-222.

Allen D. (2004): Overview of Pathogenesis of Laminitis- Models and Theories. Proceedings of Equine Laminitis Research Meeting and Panel 5-19

Bailey S. R., Marr C. M. and Elliott J. (2004): Current research and theories on the pathogenesis of acute laminitis in the horse. The Vet J 167, 129-142

Coenen M., Vervuert I. and Moessler A. (2005): Hydrogen and methane exhalation profiles of horses after consumption of grass meal (cellulose) sugar beet pulp (pectin), Oats (starch) and Jerusalem artichike (fructan) Proceedings of the 19th Symposium of the Equine Science Society, 158-159
Davidson N. and Harris P. (2002): Nutrition and Welfare In The welfare of horses. Waran N (ed) Kluwer Academic publishers Netherlands 45-76

Elliott J. and Bailey S. R. (2006): Gastrointestinal derived factors are potential triggers for the development of acute equine laminitis. $J$ Nutr. 136, 2103S-2107S

Freestone J. F., Beadle R., Shoemaker K., Bessin R. T., Wolfsheimer K. J. and Church C. (1992): Improved insulin sensitivity in hyperinsulinaemic ponies through physical conditioning and controlled feed intake. Equine Vet J 24, 187-190

Gee H. and Harris P. (2005): Condition scoring and weight estimation : practical tools. In Equine Nutrition for All Harris PA, Mair TS, Slater JD \& Green RE (eds) .Proceedings of the 1 st BEVA \& WALTHAM Nutrition symposia Harrogate, 15-24

Harris P. (2005): Influence of feeds and feeding on incidence of laminitis. Pferdeheilkunde 21, 64-65

Harris P., Bailey S. R., Elliott J. and Longland A. (2006): Countermeasures for pasture associated laminitis in ponies and horses. J Nutr 136, 2114 S-2121S

Hess T. M., Kronfeld D. S., Treiber K. H., Byrd B. M., Staniar W. B. and Splan R. K. (2005): Laminitic metabolic profile in genetically predisposed ponies involves exaggerated compensated insulin resistance. J Anim Phys Anim Nutr. 89, 431

Hoffman R. M., Boston R. C., Stefanovski D., Kronfeld D. S. and Harris $P$ (2003a): Obesity and diet affect glucose dynamics and insulin sensitivity in Thoroughbred geldings. J. Anim Sci 81, 2333-2342

Katz L., DeBrauwere N., Elliott J., Marr C. and Pfeiffer D. (2001): A retrospective epidemiological study of laminitis in one region of the UK. Proceedings of the 40th British Equine Veterinary Association Congress; 2001; Harrogate 2001 p 199

Kronfeld D. S., Treiber K. H. and Geor R. J. (2005a): Comparison of non-specific indications and quantitative methods for the assessment of insulin resistance in horses and ponies. J Am Med Ve Assoc 226, 712-719

Kronfeld D. S., Treiber K. H., Hess T. M. and Boston R. C. (2005b): Insulin resistance in the horse: Definition, detection and Dietetics J Anim Sci 83, E22-E33

Longland A. and Byrd B. (2006): Fructans and laminitis. J Nurr. 136, 2099S-2102S

Obel N. (1948) Studies on the histopathology of acute laminitis. Almqvist and Wiksells Boktryckteri Ak., Uppsala

Pass M. A., Pollitt S. and Pollitt C. C. (1998): Decreased glucose metabolism causes separation of hoof lamellae in vitro: could this be a trigger for laminitis? Equine vet. J., Suppl. 26, 133-138

Pollitt C. C. et al (2003): Equine Laminitis. AAEP proceedings, 103- 115

Splan R. K., Kronfeld D. S., Treiber K. H., Hess T. M. and Staniar W. B. (2005): Genetic predisposition for laminitis in ponies. Proceedings of the 19th Symposium of the Equine Science Society, 219- 220

Treiber K., Hess T., Kronfeld D., Boston R., Geor R. and Harris P. (2005a): Insulin resistance and compensation in laminitis-predisposed ponies ponies characetrised by the minimal model. Proceedings of the Equine Nutrition Conference, Hanover, Germany; Pferdeheilkunde 21, 91-92

Treiber K. H., Kronfeld D. S., Boston R. C. and Harris P. A. (2005b): Use of proxies and reference quintiles obtained from minimal model analysis for determination of insulin sensitivity and pancreatic beta-cell responsiveness in horses Am J Vet Res 66, $2114-2121$

Treiber K. H., Kronfeld D. S. and Geor R. J. (2006): Insulin resistance in equids: possible role in laminitis. J Nutr 136, 2094S-2098S

USDA (2000): Lameness and laminitis in US horses .USDA: APHIS: VS, CEAH, Nationalk Animal Health Monitoring system Fort Collins CO\#N318.0400

Patricia Harris MA PhD DipECVCN VetMB MRCVS

Equine Studies Group

WALTHAM Centre for Pet Nutrition

Waltham - on - the- wolds

Nr Melton Mowbray

Leics LE14 4RT, UK

pat.harris@eu.effem.com 